\title{
La concepción de la religión en la obra de La Mothe Le Vayer
}

\section{The concept of religion in the work of La Mothe le Vayer}

\author{
CARLOS GÓMEZ RODRÍGUEZ \\ I. E. S. Les Marines (Castelldefels) Barcelona
}

Recibido: 13-06-2007 Aprobado definitivamente: 25-09-2007

\section{RESUMEN}

El presente artículo examina el análisis efectuado por La Mothe le Vayer acerca del hecho religioso y su problemática en su obra Dialogues faits à l'imitation des anciens. Desde un acusado escepticismo, presenta la religión como una construcción cultural y convencional. La filosofía, en tanto ejercicio de análisis escéptico, ofrecerá una visión de la moral y la religión alejadas por completo de toda sacralizad. Serán, sin embargo, instrumentos muy útiles para el Estado y, si se administran bien, redundarán en la cohesión social y en la pax politica.

PALABRAS CLAVE

ESCEPTICISMO, CONVENCIÓN, RAZÓN DE ESTADO

\begin{abstract}
In this paper we examine the analysis carried out by La Mothe le Vayer of the religious matter and its problems in his work Dialogues faits à l'imitation des anciens. From a marked scepticism, he presents religion as a cultural and conventional entity. Philosophy, as an exercise of sceptical analysis, offers a view of morality and religion totally removed from any sacredness. Both are, however, very useful instruments for the State and, when well administered, beneficial to social cohesion and pax politica.
\end{abstract}

KEY WORDS

SCEPTICISM, CONVENTIOM, REASON OF STATE 


\section{A María Lourdes Yagües}

De Descartes a Isabel de Bohemia: «Lo que. no obstante, me produce una mayor admiración es que un conocimiento tan diverso y perfecto de las distintas ciencias que no suele poseerlo un anciano doctor que hubiera empleado muchos años en su instrucción, lo posee una princesa joven y cuyo rostro se asemeja más al que los poetas atribuyen a las Gracias que al que atribuyen a las musas o a la sabia Minerva.»

De todos los AUtORES PERTENECIENTES AL LIBERTINISMO ERUDito de la primera mitad del siglo XVII ${ }^{1}$ es François La Mothe Le Vayer (1588-1672) quien ha manifestado una mayor influencia del escepticismo. El lector de Le Vayer encontrará una buena parte del arsenal escéptico de Sexto Empírico ${ }^{2}$ en unos análisis que pretenden minar el dogmatismo de cualquier teoría pero que sobre todo estriban en una desautorización de la lógica, la física y la moral entendidas al modo aristotélico. ${ }^{3}$ Sin embargo, el escepticismo de Le Vayer alcanzará su mayor virtualidad en su alianza con la erudición. En efecto, las prolijas exposiciones comparativas efectuadas por nuestro autor acerca de las diferentes costumbres, modos de vida, creencias, etc. aportarán un efecto relativizador muy acentuado para cada una de ellas. Le Vayer concebía la realidad como un entramado tan complejo que resultaba inasequible para cualquier esquema teó-

1 Sobre el libertinismo erudito Vid. Pintard, R., Le libertinage érudit dans la première moitié du XVIIe. siècle, París, 1943, reed. Ginebra-París, 1983; Bianchi, L., Tradizione libertina e critica storica. Da Naudé a Bayle, Milán, 1988; Charles-Daubert, F., Les libertins érudits en France au XVIIe. siècle, París, 1998; «Le libertinage érudit: problèmes de définition», en Liberinage et philosophie au XVIIe. siècle, a cargo de Moreau, P. F. y Mckenna, A. (editores), Publications de 1`Université de Saint-Étienne, 1996, pp. 11-25; Rivera, A., «Libertinismo y escepticismo en la época de las guerras civiles religiosas», Caracteres literarios, Año II, $\mathrm{n}^{\circ} 3$ (1.999); Gregory, T., Genèse de la raison classique de Charron à Descartes, París, 2000.

2 Seguramente La Mothe Le Vayer conocía la obra de Sexto Empírico, Hipotiposis Pirronicas, por una versión griega editada en París en 1621 y quizá también por otra anterior en latín (ed. a cargo de Stephanus, 1562). El Adversus Mathematicos debió conocerlo por una edición latina de 1569 (a cargo de G. Hervet).

3 Un caso paradigmático de crítica escéptica lo encontrará el lector en Petit traité sceptique sur cette commune façon de parler, n'avoir pas le sens commun, Oeuvres, pp. 251272. Sobre esta obra y el escepticismo de Le Vayer Vid. Gómez Rodríguez, C., «Escepticismo, erudición y libertinismo en La Mothe Le Vayer», Endoxa. Series Filosóficas, n. 17, pp. 251-275, Madrid, 2003; «Las lecciones de la historia en Gabriel Naudé y François La Mothe le Vayer», Res Publica, 15, 2005, pp. 115-140. 
rico. ${ }^{4}$ La labor del filósofo era, en consecuencia, un desvelamiento del carácter parcial, relativo y provisional de toda teoría. Cualquier acercamiento ya sea a la naturaleza o a la realidad humana debe efectuarse con un habitus escéptico muy consciente del carácter plural y diverso de estas realidades. Del efecto del análisis escéptico emerge un haz de teorías que conviven manteniendo una suerte de simultaneidad a la hora de acometer cualquier problema filosófico. Conceder el beneficio de la exclusiva probabilidad a una de ellas sería incurrir en un dogmatismo derivado del ensombrecimiento de la alteridad, la cual debe formar parte importante de la realidad escrutada. El escepticismo, por tanto, estriba menos en considerar estéril toda investigación que en desplegar una tarea de diversificación que fructifica en una relativización de cualquier teoría tomada en su singularidad al oponerle su correspondiente contrapunto teórico. En este sentido debe entenderse la puntualización de Le Vayer, inspirada en esta célebre sentencia de Sexto Empírico: «el escepticismo es la capacidad de establecer antítesis en los fenómenos y en las consideraciones teóricas»: ${ }^{3}$ «Car nostre ignorance n'est point de ces stupides et grossieres, que les scholes appellent crasses et supines, neque est purae privationis, neque pravae affectionis, c'est une ignorance honorable, et vrayement philosophique, laquelle s'accommodant à l'obscurité de la Nature, et se mesurant à la portée de l'esprit humain, ne promet rien au delà de ses forces. C'est une ignorance discouruë et raisonnable, que je ne veux pas nommer docte, comme le Cardinal Cusan, mais à laquelle neantmoins on ne peut parvenir que par la porte des sciences, quélle laisse au dessous de soy, mettant la Sceptique un degré au dessus de tous ces superbes Dogmatiques, et de tous ces Thrasons lettrez». ${ }^{6}$

En el caso de La Mothe Le Vayer la erudición significa una puesta en práctica del escepticismo en la medida en que se destaca el carácter plural y complejo de la realidad. Desde diversos campos se contesta la verdad unívoca de aquellas verdades más asentadas en el acervo y la tradición cultural oponiendo un elenco de hechos que, vistos en su conjunto, relativizan cada una de las respuestas para ofrecer una visión nueva del problema, marcada por el perspectivismo. Cada uno de los enfoques no es más que una visión parcial e incompleta del problema que, por ello, debe ser tratado desde la totalidad de las perspectivas. La realidad, ya sea la naturaleza o el mundo del hombre, es inasequible para cualquier

4 Cfr.: «[...] C'estoit Dieu seul, qu'on devoit nommer la regle et la mesure de tout ce que contient la Nature [...] nostre humanité est encore dans ce desadvantage de la part des choses, qu'elle n'en reconnoist jamais que la superfice, et les accidens que varient incessament.» (La Mothe Le Vayer, F., «De 1'opiâtreté», Dialogues, pp. 367-368).

5 Sexto Empírico, Esbozos pirrónicos, trad. Gallego Cao, A. y Muñoz Diego, T., Madrid, 1993, p. 53.

6 La Mothe Le Vayer, «De l'ignorance louable», Dialogues faits à l'imitation des anciens, reed. Fayard, París, 1988, p. 223 
teoría; ante esta situación sólo cabe un acercamiento probable, un esfuerzo de aproximación a su inagotable versatilidad y a su dinámica inabarcable. Ese acercamiento sólo es posible desde la cautela escéptica: Le Vayer no emplea la categoría de «teoría probable» para referirse a aquella que más se acerca a la realidad de unos hechos escurridizos, sino para referirse a aquella teoría enriquecida por la convivencia con otras en una suerte de simultaneidad.

Desde esta perspectiva, el escepticismo es un $\left\langle\right.$ remedio» ${ }^{7}$ contra el dogmatismo y contra el error de querer adquirir un conocimiento absoluto, unívoco y eterno, más propio de los dioses que de los hombres. Puede ser entendido también como una «sagesse» que se eleva por encima de cualquier dogmatismo, que se distancia de cualquier teoría, incluso de aquellas que pertenecen al ámbito moral y religioso, para liberar al filósofo de un asentimiento inadecuado y empobrecedor, por más que tal asentimiento sea compartido por la inmensa mayoría de los hombres. La filosofía es para Le Vayer un instrumento que no puede caer en manos de cualquiera, sólo de aquellos capaces de mirar con los ojos abiertos la verdad que no todos pueden admitir. Así es, pues no debe escapársenos que muchos de los resortes que permiten a los Estados perpetuarse al cohesionar con eficacia a sus miembros se fundan en creencias que se deshacen ante la intervención del bisturí escéptico. Como decimos, el hecho religioso y moral constituye un buen ejemplo de ello. Precisamente la moral y la religión son instrumentos que en un Estado bien gobernado permiten el normal funcionamiento de las sociedades. Ahora bien la eficacia política que la religión y la moral pueden propiciar en un Estado eficaz nada asegura en el terreno filosófico, por ser este un terreno en el que se dirime la racionalidad o el valor de verdad de las teorías, incluídas las de carácter religioso.

Ya hemos señalado que La Mothe Le Vayer dedica una buena parte de su labor de erudición a la exposición de temas relacionados con la moral y la religión. Sigue la pauta marcada por la aplicación del décimo tropo de Enesidemo que es el de «según las formas de pensar, costumbres, leyes, creencias míticas y opiniones dogmáticas». ${ }^{8}$ Tras la presentación de exhaustivos cuadros comparativos en los que, una vez más, la variedad y el relativismo son las únicas

$7 \quad$ Cfr. «Et certes, il y en a si peu qui se servent de la philosophie selon son vray usage, et si peu qui la prennent pour remede, et non pour ornement de leur vie, comme ils devroient faire, qu'il ne se faut pas estonner s'ils attirent sur eux l'envie, et la mauvaise volonté du reste des hommes [...]» (La Mothe Le Vayer, «Le banquet sceptique», Dialogues, p. 107).

8 Cfr. Sexto Empírico, Esbozos pirrónicos, libro I, ed. cit., pp. 97 ss. 
constantes de todos ellos, Le Vayer concluye en la imposibilidad de establecer valores morales a priori. La ética es una disciplina idéntica a cualquier otra disciplina y, por tanto, adolece de las mismas limitaciones que cualquier otra: En una palabra, la ética, toda ética, es un cuerpo de afirmaciones marcado por la convención y determinado por el carácter singular de la civilización que la ha propiciado. Virtud y vicio, bien y mal son divisas cuyo valor no podrá extrapolarse del sistema en el que se han forjado. No hay un bien absoluto ni una moral prístina y trascendente comunicable al colectivo entero de los hombres al margen de la civilización que les confiere su sentido.

Tan sólo la costumbre proporcionará estabilidad a cualquier sistema axiológico y, así, no cabe apelar a instancias trascendentes ni a términos legitimadores capaces de conferir a la moral un valor absoluto. Muchísimos son los ejemplos en los que Le Vayer compara unas civilizaciones con otras para ofrecernos un espectáculo de la variedad moral que pocas dudas puede ofrecer acerca de la opinión de nuestro autor: De la ética, como de la teología, no puede hacerse ciencia alguna, por más que la costumbre ${ }^{9}$ sea a menudo confundida con la verdad en un ejemplo más de ilusión racional o dogmatismo: «On voit donc par tout une tres-grande opiniastreté pour la coustume, qu'on peut nommer un cinquiesme Element, voire une autre nature; qui fait que les enfans nouveaux nais ne font que dormir, comme y estans accoustumez dés le ventre de la mere (dit Aristote 5. De Gener. Anim., c. 1) et que depuis nous croyons tousjours faire avec raison et justice, ce que nous faisons par usage et imitation». ${ }^{10}$

Esta consideración de la moral guardará un gran paralelismo con la que nuestro autor efectuará respecto a la religión. Esto último constituirá el objeto principal de nuestro trabajo, pero antes señalemos que la concepción de la moral y la religión elaboradas por La Mothe, en la línea de toda la tradición libertina de las primeras décadas del siglo XVII, ${ }^{11}$ fue motivo de preocupación por parte de los defensores de la ortodoxia cristiana de la época. Es sabido que algunos de los más notables apologetas del cristianismo, como Marin Mersenne, condenaron el uso del escepticismo en materia de teología, religión y moral, desconfiando (con razón) de algunas protestas de fideísmo. Ya no sólo el vehemente padre

9 Sobre el uso del concepto «coutume» en La Mothe Le Vayer en cuanto a su explicación del hecho religioso-moral es muy evidente la influencia de Montaigne. A este respecto Cfr. Essais, I, 23, ed. GF-Flammarion, París, 1969 («De la coutume et de ne changer aisément une loy receüe») y 31 («Des cannibales»).

10 La Mothe Le Vayer, F., «De la philosophie sceptique», Dialogues, p. 33

11 Charron, en su obra De la Sagesse (reed. Fayard, París, 1986), afirma, como una de las conductas habituales del hombre en relación a la moral: «Condamner et rejetter toutes choses, meurs, opinions, loix, coustumes, observances, comme barbares et mauvaises, sans sçavoir que c'est et les cognoistre, mais seulement par ce qu'elles nous sont inusitées, et eslongnées de nostre commub et ordinaire.» (I, 39, p. 261). 
François Garasse, sino el más ponderado Mínimo Marin Mersenne afirma contundentemente: «Ils s'apellent Septiques, et sont gens Libertins, et indignes du nom d'homme qu'ils portent, puisque comme oyseaux funestes de la nuit n'ayans pas la prunelle assez forte pour supportes l'éclat de la vérité ils sacrifient au mensonge, et bornans toute la connoissance des hommes à la seule portée des sens, et à l'apparence exterieure des choses, nous ravalent indignement à l'état plus vil, et à la condition la plus basse des bestes les plus stupides et nous depoüillent de l'usage de tout veritable discours, et arraisonnement». ${ }^{12}$

\section{III}

El escepticismo de Le Vayer extendido al terreno religioso parte de una idea matriz: la imposibilidad de la razón para tratar de la divinidad y, en consecuencia, la inoperancia de la teología entendida como disciplina racional y pretendidadamente estructurada como una ciencia. En la importante obra titulada «Dialogue sur le subjet de la divinité», Le Vayer abre además una fisura abismal entre el saber de la naturaleza y el saber acerca de la divinidad y efectúa una crítica muy severa de dos de las aserciones clásicas de los teólogos cristianos como son la temática de la inmortalidad del alma y la providencia divina. Le Vayer afirmará repetidamente que la recepción de los contenidos de la fe cristiana convienen más con una postura escéptica y consciente del abismo que media entre el conocimiento humano y la naturaleza de la divinidad $^{13}$ que con cualquier postura dogmática. Sin embargo, un detenido examen del diálogo mencionado nos permitirá confirmar la existencia de un discurso por parte de nuestro autor extremadamente crítico acerca de los fundamentos (no sólo gnoseológicos) de la teología cristiana y de toda religión. El análisis escéptico permite diseccionar el valor de verdad de la religión en unos términos tan críticos como en cualquiera de las otras disciplinas, lo cual no quita para que una de las constantes teóricas del pensamiento de Le Vayer sea, lo hemos visto ya, el reconocimiento del valor político de la religión si esta se canaliza con prudencia por parte de las minorías gobernantes.

12 Mersenne, Marin, La Vérité des Sciences contre les septiques ou pyrroniens, París, 1625; Rpt. Stuttgart, 1969, dedicatoria. Sobre la crítica mersenniana del escepticismo remitimos a Joly, B., «La figure du sceptique dans La Vérité des sciences de Marin Mersenne», en Moreau, P. F. (dirección), Le scepticisme au XVIe. et au XVIIe. siècle, tomo II, París, 2001, pp. 257-266.

13 Cfr. «Que si nous voulons peser l'importance de ces sentences Apostoliques, et les conferer avec ce qui a esté le plus hardiment prononcé par nostre Epoche contre la temeraire arrogance des disciplines, nous y trouverons une si grande conformité, que nous serons contraints d'advoüer que la Sceptique se peut nommer une parfaicte introduction au Christianisme». (La Mothe Le Vayer, F., «De la divinité», Dialogues, p. 308). 
El diálogo «De la divinité» se abre con una intervención del personaje Orasius en la que opone el escepticismo a las opiniones de las mayorías, opiniones fundamentadas en un consensus gentium y en un dogmatismo que le parece de todo punto condenable. Por tanto, el escepticismo es aquí presentado como una suerte de sagesse liberadora que curará al pensador reflexivo de los errores aceptados comunmente: «Mais pource qu'il n'y a rien de plus opposé à nostre heureuse suspension d'esprit que la tyrannique opiniastreté des opinions communes, j'ay tousjours pensé que c'estoit contre ce torrent de la multitude que nous devions employer nos principales forces, et qu'ayant dompté ce monstre du peuple, nous viendrions facilement à bout du reste». ${ }^{14}$

Sólo debe tratarse de religión en la soledad del gabinete y ya no sólo por el deseo de apartarse de las multitudes y de sus costumbres, ${ }^{15}$ sino por el componente clandestino que posee todo análisis escéptico del hecho religioso. Orontes, en su primera réplica al personaje escéptico ya advierte de este último extremo: «Car s' il est vray qu'il n'y ait rien du tout de certain, et que toutes les sciences soient vaines et chimeriques comme vous soustenez, il s'ensuivra que nostre saincte Theologie, qui est la science des choses divines, sera fantastique et illusoire comme les autres, ce qui est une impiété, dont je vous tiens aussi esloigné, que j'apprehende que vous n'en puissiez pas esviter le soupçon». ${ }^{16}$

Tras esto se inicia el primero de los tres principales debates ${ }^{17}$ que se articulan en el diálogo. Se trata de someter a consideración la proporción existente entre el entendimiento racional y la divinidad. Orasius niega rotundamente tal proporción con las siguientes palabras: «...n'y ayant point de proportion du finy à l’infiny, et du Createur à la creature, l'immensité de cet object divin, selon que l'esprouverent Simonides et Melissus, confond tout à fait nostre entendement, comme l'excez de la lumiere du Soleil esblouït et perd nostre veuë, ut se habet visus ad visibilium summum, nempe Solem, sic intellectus ad summum intelli-

14 La Mothe Le Vayer, F., «De la divinité», Dialogues, p. 304.

15 Este es uno de los lugares comunes de la literatura libertina del momento. Otro de los máximos representantes del libertinismo erudito como es Gabriel Naudé, advierte en su obra Considérations politiques sur les coups d'État, de la inconveniencia de transmitir a la inmensa mayoría el contenido de los pensamientos más hondos de los filósofos. En el prólogo de esta obra llega a decir: «[...] este libro no se ha dado a la imprenta para que llegue al gran público [...] como los temas que trata son mucho más importantes, será forzoso que no sean tan comunes» (trad. a cargo de Gómez, C., Madrid, 1998, [p. 3]).

16 La Mothe Le Vayer, F., «De la divinité», p. 305.

17 En la obra «De la divinité» se sostienen tres grandes disputas que podríamos esquematizar del modo siguiente:

(a) ¿existe proporción entre el entendimiento humano y Dios como objeto de conocimiento? (pp. 313-317),

(b) ¿es posible probar la existencia de Dios? (pp. 317-322),

(c) ¿tiene sentido hablar de una providencia divina? (pp. 322-330). 
gibilium, nempe Deum, ${ }^{18}$ ce que Platon va déduisant fort au long au septiesme de sa Republique». ${ }^{19}$

Tanta desproporción existe entre la divinidad y el entendimiento humano-se nos dice- que parece impío rebuscar entre las cosas divinas con más curiosidad que capacidad intelectual: «il se pourroit dire que Platon auroit justement accusé d'impiété ceux qui recherchent trop curieusement les choses divines, quand il dit, maximum Deum totumque mundum dicimus inquirendum non esse, nec rerum causas multo studio indagandas, nec pium id ducimus (Leyes, 7 )». ${ }^{20}$

La antítesis a la postulación escéptica se inspira en una exposición del personaje Cota perteneciente a la obra de Cicerón De natura deorum. Cota es portavoz de determinadas doctrinas de Carnéades y de Posidonio. En el primer libro de la obra ciceroniana rebate los argumentos epicúreos de Veleyo y, con ello, su presunto ateísmo. Le Vayer comienza la réplica con una referencia a la idea de que el objeto primordial del conocimiento humano debería ser la divinidad, dado que es su causa y modelo. ${ }^{21}$ La creación del hombre por parte de Dios no parece tener un fin más importante que el de incitarle a la contemplación de su bondad, poder y sabiduría. En pocas palabras, la contemplación de la obra de Dios debe hacerle remontarse en su pensamiento desde el efecto hacia la causa, que no es otra que la misma divinidad, de la cual si bien no es posible conocer la esencia, sí es posible una contemplación admirativa de la excelencia de sus obras.

Junto a esto Le Vayer afirma que la tesis según la cual el hombre posee una noción infusa de Dios puede ser avalada por la autoridad de Aristóteles ${ }^{22}$ así como por algunos pasajes de la obra de Platón, Cicerón, Séneca y otros muchos autores. ${ }^{23}$ Ahora bien, Le Vayer para concluir esta primera discusión vuelve a oponer la antítesis de que la noción de Dios no está contenida de forma natural en la mente de los hombres, pues ello implicaría una inducción derivada del conocimiento exhaustivo y completo de todas las naciones. De hecho el testimonio de aquellos geógrafos y conocedores de diferentes regiones del planeta parece avalar el desconocimiento de Dios por parte de los habitantes de vastas regiones del planeta: «En confirmation dequoy Strabon escrit en ces termes

18 Cicerón, De natura deorum, 1, Sobre la naturaleza de los dioses, trad. Escobar, A., Madrid, 1999.

19 La Mothe Le Vayer, F., «De la divinité», Dialogues, p. 314.

20 Op. cit., pp. 314-315. Cfr. Montaigne, M., Essais, II, 12, 495 c («Apologie de Raimond Sebond»), ed. cit.

21 Cfr.: «De la divinité», (Dialogues, p. 315).

22 Vid. Aristóteles, De caelo, I, 3, Acerca del cielo, trad. de Candel, M., Barcelona, 1995.

23 «[E]t ainsi d'infinis autres autheuers, qui ont supposé cette maxime pour tresconstante». («De la divinité», Dialogues, p. 316). 
des peuples de Galice, Gallaicos Hispanos nihil de Diis sensisse perhibent; et parlant des Ethiopiens, ex iis qui torridam habitant, nonnulli sunt qui Deos esse non credunt, quoy que ce soit de leur païs, au rapport de Diodore Sicilien, qu'est procedé le premier culte des dieux, d'où vient que dans Homere le bon Jupiter va si souvent et si volontiers banqueter chez eux, apud inculpatos Aethiopes. Jean Leon nous descrivant le Royaume de Borno en Affrique, où ils vivent encores si naturellement, qu'ils tiennent leurs femmes et enfans en commun, adjouste qu'ils n'ont aucune loy, ny vestige de religion. Acosta nous fait voir que les Indiens Occidentaux n'ayans pas seulement le mot appelatif de Dieu, de sorte que ceux de Mexico et de Cusco, quoy que trouvez avec quelque sorte de religion, furent contraints de se servir du mot Espagnol, Dios, quand on le leur fit aucunement comprendre, n'ayans aucun vocable en leur langue qui respondist à celuy-là. Champlain nous asseure que ceux de la nouvelle France n’adoroient aucune Divinité» (pp. 316-317).

Si la noción de Dios fuera innata por haber sido infundida por la divinidad, ésta debería estar presente en todos y cada uno de los hombres. Al no suceder así deberá negarse la mayor: «Or si cette connoissance d'un Dieu dependoit de la lumière naturelle, personne n'en seroit privé, et il semble que nous y devrions estre tous clairvoyans. On ne peut donc pas dire quélle soit née avec nous, et que naturellement nous la possedions» (p. 317).

Así pues Le Vayer salda la primera discusión inclinando la balanza hacia las tesis más contrarias a los postulados teológicos cristianos, y esto será una constante en las dos próximas discusiones, confiriendo por tanto al conjunto un carácter netamente antiteológico.

La segunda discusión se centra en la cuestión de si es posible aportar pruebas racionales acerca de la existencia de Dios. En uno de los polos de la contienda se postulan las tesis afirmativas. Para ello se traen a colación las cinco vías tomistas de la demostración de la existencia de Dios. ${ }^{24}$ Pero mucho más espacio dedica Le Vayer a exponer la antítesis negadora de cualquier demostración de la existencia de Dios y lo hace inspirándose en la autoridad de Epicuro. De hecho, la exposición de Le Vayer es un compendio de muchos de los motivos clásicos admitidos por ateos y libertinos. Empieza mencionando el valor político que la invención de las religiones posee para el sometimiento de los miembros de cualquier comunidad, presentando pues la religión como una invención de políticos y legisladores astutos: «Mais tous conviennent entréeux, que les plus grands Legislateurs ne se sont servis de l'opinion vulgaire sur ce subject (laquelle ils ont non seulement fomentée, mais accreuë de tout leur possible) que pour emboucher de ce mords le sot peuple, pour le povoir par aprés mener à leur fantasie» (pp. 318-319).

24 Cfr. «De la divinité», Dialogues, pp. 317-318. 
Le Vayer despliega después su método erudito para ilustrar «la antítesis» negadora de las pruebas de la existencia de Dios. Primero relata algunos ejemplos del uso político de la creencia religiosa: «Ainsi Joseph Acosta nous represente les Mandarins, qui gouvernent la Chine, et contiennent le peuple dans la religion du païs, ne croyans, dit-il, quant à eux point d'autre Dieu que la Nature, d'autre vie que celle-cy, d'autre enfer que la prison, ny d'autre paradis que d'avoir un office de Mandarin. Ce n'est donc pas sans subject que Postel en son livre de orbis concordia ne nomme point les Religions autrement que du mot Persuasions; et que Prodicus Chius disoit dans Ciceron, que les choses utiles à la vie avoient esté facilement deïfiées. Car c'est par là (disent-ils) que ces habiles hommes introduisirent leurs divinitez, Deus est mortali juvare mortalem, et ce qui suit de notable sur ce subject dans Pline, au second de son histoire chapitre septiesme» (p. 319).

Después, muestra de qué modo la identificación de los objetos de culto con algunos beneficios recibidos por el pueblo carece del aval de la razón pero, sin duda, ha sido otra buena estrategia en el uso instrumental de la religión por parte de los políticos.

Le Vayer apela al testimonio de los antiguos para afirmar que los grandes hombres o los de mayor inteligencia han comprendido que los dioses eran forjados por los hombres para mantener viva una creencia y un temor que resultan eficaces en el gobierno de las masas populares; naturalmente la prudencia les hace guardar silencio, pues saben del efecto negativo que el descubrimiento de los secretos podría causarles: "Aussi veulent-ils [en referencia a autoridades como Diógenes Laercio, Platón, etc. ${ }^{25}$ ] que les plus grands hommes se soient assez apperceus de cette imposture divine, s'il faut ainsi parler, quoy que depuis Socrate l'apprehension de la ciguë les ait tenus dans le silence» (p. 320).

Sin embargo, aunque la antigua comedia griega manifestaba una gran libertad en el tratamiento del tema de la divinidad, ${ }^{26}$ no sucede lo mismo con Aristóteles, atento al consejo de su maestro respecto a la cautela con que debe hablarse de los dioses: «mais bien qu'Aristote fust fort retenu par l'exemple que nous venons de dire de son maistre, et que pour ce subject il ait jetté beaucoup de sable aux yeux de ceux qui devoient lire ses escrits sur ce subject [...]» (p. 320), si bien una lectura atenta de su obra, como la efectuada por Averroes, permite identificar en el Estagirita la divinidad con la naturaleza: «[...] Il a tellement attaché son Dieu aux necessitez Naturelles dans la direction et gouvernement de l'univers, que la pluspart a estimé qu'il ne reconnoissoit point d'autre Dieu que la Nature mesme» (p. 320). 
El naturalismo subyacente en el pensamiento de Aristóteles no sólo ha sido visto por Averroes, sino por pensadores como Cardano y Postel. Le Vayer subraya la precisión y la profundidad de la lectura averroísta de Aristóteles, como se deduce de las palabras siguientes, concibiendo así la religión de forma muy distinta a la que se deriva de otras lecturas de Aristóteles mucho más concordantes con el Cristianismo, como era la importante línea tomista por ejemplo: «Averroes, surnommé son Commentateur par excellence, comme celuy qui a le mieux reconnu son Genie [...]» (p. 320).

Debemos destacar entre las autoridades invocadas por Le Vayer para desautorizar toda prueba de la existencia de Dios la de Pietro Pomponazzi, del que afirma su teoría de la doble verdad: No es posible afirmar la existencia de Dios ni la inmortalidad del alma desde las reglas de la razón y de la filosofía. Puede, por el contrario, no el filósofo, sino el hombre entregarse a una creencia fideísta para llegar a Dios.

A la temática del temor para instituir las religiones, de la eficacia estrictamente política de las creencias religiosas mayoritarias, del fideísmo como contrapunto de la irracionalidad de la creencia religiosa, añade otro argumento clásico aducido por los ateos: la injusticia moral y la nula compensación que reciben los justos en este mundo, donde el injusto sale a menudo altamente beneficiado, como se desprende del siguiente caso: «Mais Diagoras fut si hardy, qu'il osa bien escrire, dit Hesychius, orationes de turribus praecipitantes, où il rendoit raison de son esloignement de la commune opinion des Dieux, aprés avoir esté quelque temps auparavant tres-superstitieux, ce changement estant venu, comme nous apprenons de nostre cher patron Sextus, d'avoir consideré l'impunité d'un homme duquel il avoit esté offensé, et lequel en avoit esté quitte pour se parjurer envers les Dieux impunément» (p. 321). ${ }^{27}$

La tercera discusión acomete el tema de si la divinidad es providente y, por tanto, mantiene el cuidado y la atención de los asuntos humanos o, por el contrario, el mundo se mueve autónomamente y de espaldas a cualquier tipo de dirección divina. La tesis que afirma la providencia divina se apoya en el consensus gentium, avalado además por la opinión y el pensamiento de importantes autoridades. Debe no sólo, nos dicen, atribuirse a Dios la dirección general del universo y el movimiento reglado de toda la maquinaria cósmica, sino un cuidado particular y completo de cuanto sucede en el mundo sublunar, especialmente en lo referente a la conducta de cada uno de los hombres, para proceder a una ulterior recompensa de las acciones virtuosas o al castigo de los actos reprobables. A cuantos aducen que esto sería equivalente a querer atribuir a la divinidad actos indignos y cuidados más propios de los hombres que de la excelencia de Dios, los defensores de la providencia replican que tal forma de 
argumentar no responde a la verdad y más bien es el efecto de la debilidad del conocimiento humano, que atribuye a Dios formas de acción que derivan de nuestra defectuosa forma de razonar. En suma, la aparente antropomorfización de la divinidad es el resultado de la forma humana imperfecta de comprender los asuntos divinos: «Mais le mauvais jugement qui se fait en cela des actions de Dieu, procede des defauts de nostre vicieuse ratiocination, qui ne peut rien comprendre qui suivant sa portée, ny discourir des choses divines qu' humainement; de sorte que ce que nous pensons estre passion en Dieu, luy est indolence, ce que nous estimons le peiner, le delecte, et ce que nous croyons qu'il mesprise et ne voit pas, luy est incessamment present [...]» (p.325).

Ya desde las historias antiguas se pueden recabar numerosos ejemplos de la intervención divina en los asuntos humanos. ${ }^{28}$ Incluso se aduce algún ejemplo de Aristóteles, tomado de la Magna Moralia, I, 5, donde dice que debe temerse a los dioses, si bien ya sabemos que Le Vayer había señalado la lectura averroísta de Aristóteles como la más profunda. El uso retórico de la autoridad de Aristóteles para defender la providencia divina parece corroborarse con la acotación que el propio Le Vayer efectúa en el texto que ahora analizamos: «Ce n'est donc pas sans subject qu'Aristote (paroissant plus religieux icy que beaucoup ne veulent qu'il ait esté) pour montrer que la vertu consiste en une certaine mediocrité, laquelle se corrompt egalement par l'excez, comme par la defectuosité, en donne cet exemple dans la Vaillance, que si quelqu'un estoit si peu apprehensif, et si intrepide qu'il ne craignist pas mesme les Dieux, ce ne seroit plus force et valeur en luy, mais ce seroit folie et pure demence» (p. 324).

La antítesis, como en otras ocasiones, merece un tratamiento mucho más cuidadoso y exhaustivo por parte de La Mothe Le Vayer. Comienza haciendo referencia a la pertinencia de un seguimiento de la autoridad de Epicuro y sus seguidores para una negación razonada (y «llena de coraje», nos dice) de la providencia divina, de la que han derivado muchas otras críticas posteriores: «Mais entre tous ceux qui ont pris cette licence, nous n'en voyons point qui se soient hardiment expliquez comme Epicure et les siens; car tous les autres se sont monstrez respectueux envers les opinions receuës, se sont accomodez timidement au temps, et gauchissant avec le plus de dexterité qu' ils ont peu, se sont contentez de faire paroistre dans leurs escrits quelques lumieres obscures de leurs pensées; là où Epicure se vante de śestre seul avec ceux de sa secte, et le premier genereusement laissé entendre sur ce subject, et d'avoir prononcé courageusement le plus interieur de son ame, en declamant ouvertement contre les faulses opinions de la providence des Dieux, et contre les abus introduicts dans la vanité des religions» (p. 326). 
También Sexto Empírico reconoce la autoridad de Epicuro, como se deduce de la exposición efectuada por Cicerón en el libro segundo de su De Natura deorum. Entre los latinos seguirán la misma línea argumental Enio, ${ }^{29}$ Virgilio, ${ }^{30}$ Juvenal ${ }^{31}$ o Séneca. ${ }^{32}$ Podrían, dice Le Vayer, añadirse pasajes de muchos otros autores y todos argumentarían en los términos siguientes:

A) En primer lugar, los dos atributos de Dios como son la bondad máxima y el pleno poder no parecen cuadrar con una creación llena de defectos: «Or est-il que nous y remarquions des defauts infinis; mille monstres qui font honte à la nature; tant de fleuves qui gastent des païs, ou tombent inutilement dans la mer, lesquels fertiliseroient heureusement des contrées desertes pour leur trop grande aridité; tant de coups de foudre qui tombent inutilement sur les cimes du Caucase, laissant toute sorte de crimes impunis (ce que vouloient dire, à mon advis, les anciens qui les disoient fabriquez par ce boiteux Vulcain, comme ceux qui alloient et donnoient tout au rebours de bien) bref, il s'y observe par ceux qui se voulus estendre sur ce subject des manquemens innombrables, soit dans l'ordre general, soit dans le particulier» (p. 328).

B) Parece contradictorio con la providencia el hecho de que la maldad humana se vea recompensada a menudo con la buena fortuna, mientras que los actos más virtuosos y respetuosos de la religión se vean acompañados del infortunio para quienes los practican: «[...] [P]ersonne ne peut contredire pour estre infinies et journalieres, de la prosperité des meschans, et de la calamité des plus vertueux et des plus religieux. Il n'y eut jamais une plus heureuse navigation que celle de ce tyran de Syracuse au retour de Locres, où il avoit commis ce fameux sacrilege, violant y pillant le temple de Proserpine» (p. 329).

Con lo cuál debe concluirse que si todo sucede de forma azarosa o a causa de un destino ciego, se considerará inútil toda plegaria y toda devoción, excepto

29 Cfr.: «Ego Deum genus esse semper dixi, et dicam Coelitum/ Sed eos non curare opinor quid agat humanum genus». (Enio; recogido en La Mothe Le Vayer, op. cit., p. 327.

30 Cfr.: «Foelix qui potuit rerum cognoscere causas, / Atque metus omnes, et inexorabile fatum / Subjecit pedibus, strepitumque Acheruntis avari» (Virgilio, Georgicas, 2; recogido en op. cit., p. 327).

31 Cfr:: «Sunt in fortunae qui casibus omnia ponunt,/ Et nullo credunt mundum rectore moveri, /Natura volvente vices et lucis, et anni, /Atque ideo intrepidi quaecunque altaria tangunt». (Juvenal, Sátiras, 13; recogido en op. cit., p. 328).

32 Cfr.: «[...] [P]errumpet omne/Solus contemptor levium Deorum, / Qui vultus Acherontis atri,/ Qui Styga tristem non tristis videt, / Audetque vitae ponere finem;/Par ille Regi, par superis erit» (Seneca, in Agam.; recogido en op. cit., p. 328). 
para embridar a quienes son incapaces por sí mismos de seguir una conducta recta: «Que si toutes choses sont predestinées inevitablement du sort et de la fortune, sans que les Dieux s'en entremettent, comme les desordres presupposez le monstrent assez, el s'ensuit d'une consequence necessaire que toutes nos devotions, nos latries, nos prieres et oraisons, sont choses vaines et ridicules, inventées par ceux qui vouloient profiter de leur introduction, et confirmées en suitte par l'accoustumance aveugle et populaire, voire mesme par des plus clairvoyans, qui estimoient cette fiction fort utile à reprimer les plus vicieux» (p. 329).

Tras la conclusión del tercer debate, Le Vayer compara el espectáculo de la variedad de religiones con un Océano proceloso en el que será imposible escapar de tempestades que finalmente nos conducirán a un «espiritual naufragio». Con ello nos remite a la imagen lucreciana del suave mare magno, manteniendo, pues, la influencia del epicureísmo en su exposición.

Tantas, nos dice, son las religiones instituídas sobre el mundo ${ }^{33}$ que cada una de ellas se asemeja en cierto sentido a esas teorías astronómicas que con todo tipo de artificios geométricos pretenden dar cuenta de los fenómenos observables en los cielos: «[...] [C]omme Ptolomée ou ses devanciers inventerent les hypotheses des epicycles, des excentriques ou concentriques, et de telle autres machines fantastiques, pour rendre raison des phainomenes ou apparences celestes, chascun pouvant faire capricieusement le mesme à sa mode, comme de supposer la mobilité de la terre, et le repos du firmament, ou chose semblable, moyennant qu'il sauve et explique methodiquement ce qui tombe soubs nos sens des choses du Ciel» (p. 330).

De modo que si de la imaginación de algún hombre saliese una nueva teoría que diese cuenta de los fenómenos morales, de las formas de vida más justas y razonables, de la forma de reglar las acciones de los hombres, habría que recibirla de buen grado como se recibe la teoría copernicana por teorizar el movimiento de los cuerpos celestes de forma sencilla y eficaz, ${ }^{34}$ pues la religión, cualquier religión, no es sino un sistema particular que pretende dar cuenta de los fenómenos morales y de las apariencias de nuestra dudosa ética: «[...] [U]ne religion, conceuë de la sorte, n'est autre chose qu'un systeme particulier, qui

33 Cfr. «[...] [D]epuis le premier homme il n'y ait eu que trois cens soixante et cinq sectes de religions, mais on voit aisément que c'est un nombre affecté, comme esgal aux jours de l'an». (op. cit., p. 330).

34 Cfr. op. cit., pp. 330-331. 
rend raison des phainomenes morales, et de toutes les apparences de nostre douteuse Ethique» (p. 331).

En el mosaico abigarrado y variado de las religiones apenas hay una sola que no pretenda y haga creer a sus seguidores que posee la exclusividad de la certeza, desposeyendo de esto mismo a todas las demás. Por ello la casi totalidad de los creyentes están dispuestos a luchar «jusques à la derniere goutte de son sang» (p. 331) por defender la religión propia y combatir las demás más que en cualquier otro tema o empresa. Así, los príncipes más capaces son sabedores del inmenso valor que supone en sus manos la tenencia de un arma como la religión, si quieren mantener su principado cohesionado y obediente a su mandato: «Ce qui procede de ce que comme l'unité de religion lie et unit, selon son etymologie, à religando, la diversité deslie et divise merveilleusement» (p. 331).

De modo que toda religión es idéntica a las demás si cumple con la misión de unir al hombre con el hombre, bajo la promesa de unir al hombre con Dios: «Il y en a toutefois qui ont eu toutes religions pour indifeferentes, ou egalement bonnes [...]» (p. 332). La identidad de todas las religiones, la igualdad establecida por el cumplimiento de una misma eficacia pedagógica y cohesionadora del colectivo que conforma el cuerpo social, cuando, eso sí, las religiones no derivan hacia la mera superstición por el uso ineficaz y excesivamente sectario de quienes las han de mantener vivas, es algo que debe ser comprendido por el filósofo. Le Vayer, en una línea teórica similar a la sostenida en su obra $L a$ vertu des payens, coincidente también con muchas apreciaciones de Montaigne y Charron sobre todo en el Petit traité, ${ }^{35}$ afirma la justicia y el cristianismo prístino de todos aquellos que observan en su conducta un uso recto de la razón natural. Le Vayer llega a decir, como podemos apreciar en el texto siguiente, que incluso los ateos, si son virtuosos son en el fondo cristianos: «[...] [T]ous ceux qui suivent le droit usage de la raison naturelle, fussent-ils mesme reputez athées, ne laissent pas d'estre veritablement Chrestiens; puis que Jesus-Christ n'est autre chose que ce Verbe divin, et cette raison naturelle, de laquelle tous les hommes sont participans [...]» (p. 333).

De modo que muchos hombres que han sido tenidos por paganos entrarían de pleno derecho si no en el seno de la Iglesia, sí en el Cristianismo por haber conducido sus vidas con arreglo a la rectitud: «Socrate, Heraclite, et assez D'autres, tenus pour barbares, et sans culte divin, estoient neantmoins veritablement Chrestiens, puis qu' ils observoient les loix de cette droitte raison [...] comme si les vertus morales estoient un leurre de la grace Divine en tous ceux qui les prattiquent [...]» (pp. 333-334). 
$\mathrm{El}$ análisis de las diferentes religione $\mathrm{s}^{36}$ nos muestra que difieren en su exterioridad, en los cultos y en los nombres que otorgan a sus profetas y dioses, pero en su interioridad un mismo núcleo pervive y las hace una y la misma religión que cumple una función única. La inmensa mayoría promete la inmortalidad del alma, una restitución de la justicia que los justos no han podido gozar antes de la muerte y fomenta el temor de un castigo para quienes transgredan las normas morales instituídas. Algunas prometen incluso la resurrección de la carne, aunque no todas. Unos prefieren religiones muy ceremoniosas y llenas de leyes y prescripciones, mientras que otros abogan por una adoración de Dios interior y por una religión exenta de boato ritual. En suma, hay tanta variedad y disparidad en el ejercicio de la religiosidad como en cualesquiera otras costumbres idiosincráticas de las diferentes comunidades: «Nous nous lavons le front d'eau beniste à l'entrée des Eglises, comme les Payens faisoient d'eau lustrale; les Mahometans se lavent les pieds et les parties honteuses du devant et du derriere aux portes de leurs Mosquées; les Indiens Occidentales de 1'Isle Espagnole pensoient estre purgez de tout crime quand ils s'estoient descharguez l'estomac par le vomissement au pied de leurs autels» (p. 336).

El examen racional de las religiones ofrece un espectáculo lleno de contradicciones y de extravagancias. Con la religión sucede como con cualquier otra disciplina. Si se aborda su estudio con un desmesurado deseo de comprensión racional habremos de topar con la misma impermeabilidad que nos ofrecen muchas otras ciencias. De hecho, el intento de someter cualquier realidad natural o humana a esquemas intelectuales o sistematizadores está condenado a la más obstinada esterilidad intelectual. Por ello Le Vayer despliega nuevamente su labor erudita para mostrar la diversidad y desacuerdo que resulta de la comparación de unas religiones y otras, de entre las que, como señalábamos anteriormente, el cristianismo no será sino un caso más.

Así, unos prefieren teñir sus ofrendas de sangre: «Les uns ont rougy ces autels de sang humain, comme les Carthaginois, et dernierement ceux du Perou, qui immoloient jusques à leurs propres enfans à leurs idoles; les autres ont preferé les sacrifices que se faisoient farre pio et saliente mica, et le coeur contrit et humilié aux plus solemnels holocaustes, et à toutes les hecatombes, voire chiliombes Olympiques» (p. 336).

Unos prefieren demandar de la divinidad aquello que es necesario, mientras que otros prefieren dejarlo todo a la voluntad de Dios. ${ }^{37}$ Unos consagran el sábado, otros cualquier otro día. ${ }^{38}$ Unos gustan de templos soberbios mientras

36 La Mothe Le Vayer efectúa un repaso de las diferentes religiones de las Indias Orientales (vid. op. cit., pp. 334 ss.).

37 Cfr., op. cit., p. 336.

38 Cfr. loc. cit. 
que otros: «au rapport d'Herodote, se mocquoient de tout cela» (p. 337); unos forjan imágenes de la divinidad mientras otros niegan que tal cosa pueda hacerse, tachándola además de impía.

Unos dicen que la religión debe quedar subordinada a las leyes del Estado, mientras que otros preferirían someter el Estado a la Iglesia. ${ }^{39}$

Unos quieren vincular los preceptos religiosos con la razón y la ley natural mientras que otros colocan la ley religiosa en la esfera de lo sobrenatural. ${ }^{40}$

Unos quieren llevar la piedad al máximo extremo posible; otros, siguiendo a Plutarco, entienden que tal cosa sería una recaída en la superstición: «Les uns s'imaginent qu'on ne peut estre trop religieux, l'excez estant loüable aux choses bonnes, et qu'en tout cas il vaut mieux estre supertitieux qu' impie ou athée; les autres favorisent l'opinion de Plutarque, qui a fait voir en un traicté exprés le revers de cette medaille» (p. 339).

En este sentido, queremos destacar uno de los pasajes a nuestro juicio más significativo del texto que estamos examinando. Llamamos sobre él la atención para efectuar después algunas consideraciones. He aquí el texto: «[...] l’atheïsme ne troubla jamais les Estats, mais il rend seulement l'homme plus prevoyant à soimesme, comme ne regardant pas plus loing. Et je vois (adjouste-il) que les temps inclinez à l'atheïsme, comme le temps d'Auguste Cesar, et le nostre propre en quelques contrées, ont esté temps civils, et le sont encores; là où la superstition a esté la confusion de plusiers Estats, ayant porté à la nouveauté le premier mobile, qui ravit toutes les autres spheres de gouvernements, c'est à sçavoir le peuple» (p. 339).

En primer lugar, de igual modo que el paganismo era compatible con la virtud, con una ética natural que puede fructificar al margen de toda confesión religiosa, el ateísmo o esa misma ausencia de confesión religiosa, no impide al espíritu una cierta «pieté naturelle» ni una capacidad para la virtud y el respeto a las leyes. Por el contrario, es la superstición ${ }^{41}$ o la vivencia excesivamente intensa del hecho religioso, o la implantación de religiones intolerantes, sectarias, lo que ha provocado, si seguimos las enseñanzas que nos proporciona la historia, uno de los males mayores que pueda acaecer en el Estado, como es el advenimiento de ese tipo tan grave de convulsiones que son las provocadas por los movimientos populares, capaces de arrastrar en su rebelión a todas las demás esferas de la sociedad. En conclusión, la pervivencia de la sociedad requiere de una religiosidad templada y tolerante, alejada del fanatismo, la superstición y el extremo. Acabamos de ver que incluso una cierta inclinación al ateísmo y a

39 Cfr., op. cit., p. 337.

40 Cfr., op. cit., pp. 337-338.

41 Sobre ello vid. Montaigne, M., Essais, I, 32 («Qu'il faut sobrement se mesler de juger des ordonnanances divines»). 
una fundamentación de la moral basada en la ley natural ha proporcionado una pax o eso que Le Vayer denomina un temps civil.

Si proseguimos el examen de las contradicciones que todo sistema religioso comporta, a juicio de La Mothe, veremos que son muchos los que propugnan y exigen el temor de Dios como método para mantener con eficacia los preceptos religiosos más extravagantes. Por eso Charron, en su obra De la Sagesse ${ }^{42}$ recalca la enorme dificultad que entraña vincular cualquier religión con las reglas del sentido común.

No menos diversidad y confusión encontraremos en el modo en que Dios ha sido concebido y representado: «Les uns ont fait des Dieux masles, les autres femelles, Trismegiste et Orphée nous representent le leur Androgyne; et Synilius dit du vrai Dieu dans ses hymnes, qu'il est pere et mere, masle et femelle tout ensemble./ Les uns, comme Zenon et Xenophanes, ont fait Dieu de figure toute ronde, c'est pourquoy Platon vouloit que le monde eust encores la forme spherique, quod conditoris esset rotunda figura; les autres ne se peuvent imaginer de Dieux, s'ils ne sont comme ceux d'Epicure, de figure humaine; et nous voyons que la Theanthropie sert de fondement à tout le Christianisme» (p. 340).

Hay religiones estrictamente monoteístas, mientras otras han deificado una multitud de elementos, hasta tal punto que, según Le Vayer, podría decirse lo siguiente: «Car je ne pense pas non plus que le sage Charron, qu' il y ait rien en la nature, qui náit esté en quelque temps et par quelqu'un Deïfié, cette apotheose s'estant estenduë depuis les choses les plus grandes et considerables, jusques aux plus petites et chetifves (tesmoin le vase dans lequel Amasis avoit lavé ses pieds) et depuis la convexité du premier Ciel, où les Peripatetiques placent leur premier Moteur, jusques au centre de l'univers» (p. 342).

$\mathrm{Si}$ algunos han divinizado la naturaleza en su totalidad, identificándola con Dios mismo, ${ }^{43}$ debe reconocerse que pocas personas han levantado la vista al cielo sin venerarlo o en su totalidad o en alguno de sus elementos. ${ }^{44}$ Los pitagóricos preferían, desde la contemplación de la armonía de los cielos, concluir que «Dieu n'est autre chose qu'un nombre, et une harmonie» (p. 343).

Pero el examen minucioso y comparado de las creencias humanas nos permite también parar atención en quienes descendiendo de los cielos han querido divinizar los elementos: «qu'Empedocle a le premier Deïfiez, au nombre de quatre. Platon estime dans Diogene, que les Dieux soient pour la pluspart ignées. [...] [D]e sorte qu'il n'y a eu si petit ruisseau qui n'ait eu son Genie particulier [...]. Car non seulement les plus nobles, et les plus utiles d'entre ses animaux ont

43 Cfr. op. cit., p. 342.

44 Cfr. op. cit., pp. 342-343. 
esté adorez par les Egyptiens, et autres peuples qui sén trouvoient beneficiez; mais mesme les plus vils, et les plus malfaisans d'entr'eux» (pp. 343-344).

Todas estas extravagancias, continúa Le Vayer tras realizar un cumplido repaso de las religiones arraigadas en numerosos pueblos de todos los continentes, deben tenerse en poco si se comparan con otras formas religiosas procedentes del extremo oriente: «Mais que peut-on trouver d'estrange en toutes ces extravagances de religion, quand ce Bolognois Bartheme nous donne pour certain, qu' il y a des Calecutois, et Mercator dit des Chinois, qui font profession d'adorer le diable mesme, soubs une figure estrange, asseurans qu'hors la creation du monde Dieu ne s'en est plus voulu mesler, et l'a laissé en la conduitte de ce mauvais Demon, auquel seul pour ce subject ils croyent que nous devons adresser nos voeux et nos prieres; à la mode de nos Sorciers de pardeça qu'on dit souffrir jusques au martyre dans leur religion du Sabbath. Que si nous voulions esplucher plus par le menu les prodigieuses resverier de certains peuples du nouveau monde sur la reconnoissance d'une Divinité, nous aurions d'autant plus de subject, sans doute, de prendre une extréme compassion de nostre pauvre humanité» (pp. 346-347).

Aquí topamos con una de las conclusiones extraídas por La Mothe Le Vayer en el diálogo que estamos examinando: Si sometemos a examen racional la naturaleza y esencia de los dioses; si observamos con mirada penetrante y libre de prejuicio el contenido de las diferentes religiones, nos encontraremos ante un escenario lleno de extravagancia y de arbitraria variedad, sin acuerdo alguno que pueda unir o subsumir a las unas dentro de las otras, sin elementos constantes y regulares como demandaría la posibilidad de una teología especulativa. No hay tal cosa y por eso, una «extrema compasión ante la pobre humanidad» invade el espíritu tanto por la contemplación de ese espectáculo de extravagancia como ante la debilidad del espíritu humano que, cuando ha intentado pensar la trascendencia, no ha sido capaz de llegar más lejos que en la imposible comprensión de la naturaleza. El uso del raciocinio es, por tanto, estéril cuando se pretende aplicar a cualquiera de los temas escrutados habitualmente por los teólogos. Las contradicciones más extremas, la arbitrariedad, la extravagancia $\mathrm{y}$, en todo caso, la inconsistencia intelectual afectan a cualesquiera propuestas teológicas porque todas sobrepasan el poder del espíritu humano: «[...] Vouloir trouver la Theologie dans la Philosophie, c'estoit comme chercher les vivans parmy les morts» (p. 350).

Si querer someter el orden natural o aquello que aparece cercano a la mirada humana a la racionalidad es harto problemático, querer penetrar en el terreno nebuloso e ignoto de la divinidad, de su esencia, de sus designios y voluntad, es empresa condenada al fracaso de antemano: «C'est lors que ce temeraire Icare, pour s'estre voulu trop haut eslever vers le Ciel, se trouve honteusement et calamiteusement precipité dans une mer de confusion, et d'erreur, qui est cet Ocean immense des sciences» (p. 352). 
Sólo el «habitus escéptico» distancia al filósofo del error y de la ofuscación de verse enredado en cualquier dogmatismo, pues no es otro el resultado de verse entregado a cualquier propuesta teológico-religiosa. Sólo desde el escepticismo puede otorgarse a la religión su auténtico estatus en el conocimiento humano, la de ser admitida de fides exclusivamente: «Faisons donc hardiment profession de l'honnorable ignorance de nostre bienaimée Sceptique, puis que c'est elle seule qui nous peut preparer les voyes aux connoissances revelées de la Divinité, et que toutes les autres sectes Philosophiques ne font que nous esloigner, nous entestant de leurs dogmes, et nous embroüillant l'esprit de leurs maximes scientifiques, au lieu de nous éclaircir et purifier l'entendement» (pp. 350-351).

Desde una metodología escéptica, capaz de diseccionar el fenómeno religioso de forma penetrante y sin prejuicio, se accede a una distancia y perspectiva capaz de facilitar la comprensión de diferentes cuestiones fundamentales: a) la imposibilidad de racionalizar el hecho religioso y el referente trascendente al que la teología apunta, b) la inconsistencia intelectual de toda prueba de la existencia de Dios, así como de los discursos tradicionales acerca de la inmortalidad del alma, c) el error inherente a toda afirmación de la providencia divina, d) la igualdad de unas y otras religiones en cuanto todas son un sistema convencional de origen estrictamente humano y cuya función es civil y política y e) el peligro de llevar la devoción religiosa hacia el extremo de la superstición, con el consiguiente perjuicio de la convivencia en el seno del cuerpo político.

Según esto el filósofo debe mantenerse a distancia intelectual ${ }^{45}$ de cualquier confesión religiosa para poder quedar en condiciones de efectuar un análisis en el que unas religiones y otras quedan igualadas por unas constantes teóricas comunes con cualquier otro sistema convencional y el cumplimiento, si son bien instrumentalizadas, de una función cívico-política que hemos intentado analizar ya. El espíritu humano mantendrá así la lucidez que deriva del escepticismo y, apartándose de la senda transitada por las mayorías, podrá orientarse hacia aquello que es propio de su condición: «Il me semble qu'on ne peut mieux appliquer ce caprice poëtique, qu'à la condition ordinaire de nostre esprit, lequel se tenant dans les termes naturels, et que Dieu luy a prescrit, possede le plus grand de tous les Royaumes, qui est l'empire qu'il a sur soimesme» (p. 351).

\section{REFERENCIAS BIBLIOGRÁFICAS}

ARISTOTELES, 1995: De caelo, I, 3, Acerca del cielo, trad. de Candel, M., Barcelona: Gredos.

45 La fe no es una operación filosófica ni intelectual, es un recurso posible cuando se agota la vía del conocimiento. 
BIANCHI, L. 1988: Tradizione libertina e critica storica. Da Naudé a Bayle, Milán: Franco-Angeli.

CHARLES-DAUBERT, F. 1998 : Les libertins érudits en France au XVIIe. siècle, Paris: P.U.F.

CHARLES-DAUBERT, F. 1996: «Le libertinage érudit: problèmes de définition», en Liberinage et philosophie au XVIIe. siècle, a cargo de Moreau, P. F. y Mckenna, A. (editores), Publications de 1’Université de Saint-Étienne, pp. 11-25.

CHARRON, P. 1986: De la Sagesse, París: Fayard.

CICERÓN 1999: De natura deorum, 1, Sobre la naturaleza de los dioses, trad. Escobar, A., Madrid: Gredos.

GÓMEZ RODRÍGUEZ, C. 2003: «Escepticismo, erudición y libertinismo en La Mothe Le Vayer», Endoxa. Series Filosóficas, n. 17, pp. 251-275.

GÓMEZ RODRÍGUEZ, C. 2005: «Las lecciones de la historia en Gabriel Naudé y François La Mothe le Vayer», Res Publica, 15, pp. 115-140.

GREGORY, T. 2000: Genèse de la raison classique de Charron à Descartes, París: P.U.F.

JOLY, B., 2001: «La figure du sceptique dans La Vérité des sciences de Marin Mersenne», en Moreau, P. F. (dirección), Le scepticisme au XVIe. et au XVIIe. siècle, tomo II, París: Albin Michel, pp. 257-266.

LA MOTHE LE VAYER, F. 1970: Petit traité sceptique sur cette commune façon de parler, n'avoir pas le sens commun-Oeuvres, Ginebra: Slatkine Reprints.

LA MOTHE LE VAYER, F. 1988: Dialogues faits à l’imitation des anciens, París: Fayard.

MERSENNE, M. 1625/1969: La Vérité des Sciences contre les septiques ou pyrroniens, París, 1625; ed. Rpt. Stuttgart, 1969.

MONTAIGNE 1969: Essais, París: GF-Flammarion,.

NAUDÉ, G. 1998: Consideraciones políticas sobre los golpes de Estado, trad. a cargo de Gómez Rodríguez, C., Madrid: Tecnos.

PINTARD, R. 1943/1983: Le libertinage érudit dans la première moitié du XVIIe. siècle, París: Slatkine, 1943, reed. Ginebra-París, 1983.

RIVERA, A. 1999: «Libertinismo y escepticismo en la época de las guerras civiles religiosas», Caracteres literarios, año II, $n^{\circ} 3$.

SEXTO EMPÍRICO 1993: Esbozos pirrónicos, trad. Gallego Cao, A. y Muñoz Diego, T., Madrid: Gredos.

Carlos Gómez RodríGueZ es Profesor de Filosofía en el I.E.S. «Les Marines» de Castelldefels (Barcelona).

\section{Líneas de investigación:}

Ha trabajado sobre la filosofía de la primera mitad del siglo XVII. Ha publicado ensayos sobre Mersenne, Naudé, La Mothe, etc., en diferentes revistas internacionales. Ha traducido, entre otras cosas, Las Consideraciones políticas sobre los golpes de Estado de Gabriel Naudé (Tecnos, Clásicos del Pensamiento, $\mathrm{n}^{\circ}$ 133, Madrid, 1998). 
Publicaciones recientes:

«Las lecciones de la historia en Gabriel Naudé y F. La Mothe Le vayer», Res Publica, $\mathrm{n}^{\circ}$ 15 (2005), pp. 115-140.

«La crítica moral y religiosa en Cyrano de Bergerac», Contrastes, X (2005), pp. 5-20.

Dirección postal:

C/ Doctor Zamenhof, 45, 3 4 ${ }^{\mathrm{a}}$, 08800. Vilanova i la Geltrú (Barcelona).

Direcciónelectrónica: carlos_irene@hotmail.com 